\title{
Power, Competitiveness, and Advice Taking: Why the Powerful Don't Listen
}

\section{Citation}

Tost, L. P., F. Gino, and R. Larrick. "Power, Competitiveness, and Advice Taking: Why the Powerful Don't Listen." Organizational Behavior and Human Decision Processes 117, no. 1 (2012): 53-65.

\section{Published Version}

http://www.sciencedirect.com/science/article/pii/S0749597811001233

\section{Permanent link}

http://nrs.harvard.edu/urn-3:HUL.InstRepos:10996800

\section{Terms of Use}

This article was downloaded from Harvard University's DASH repository, and is made available under the terms and conditions applicable to Open Access Policy Articles, as set forth at http:// nrs.harvard.edu/urn-3:HUL.InstRepos:dash.current.terms-of-use\#OAP

\section{Share Your Story}

The Harvard community has made this article openly available.

Please share how this access benefits you. Submit a story.

Accessibility 
Running Head: POWER AND ADVICE TAKING

Power, Competitiveness, and Advice Taking: Why the Powerful Don’t Listen

\author{
Leigh Plunkett Tost \\ University of Washington \\ Francesca Gino \\ Harvard University \\ Richard P. Larrick \\ Duke University
}

Forthcoming in Organizational Behavior and Human Decision Processes

\begin{abstract}
Author Note
The authors greatly appreciate the support and facilities of the Center for Behavioral Decision Research at Carnegie Mellon University and of the Center for Decision Research at the University of North Carolina at Chapel Hill where the studies were conducted. Please address correspondence to $\underline{\text { ptost@uw.edu. }}$
\end{abstract}




\begin{abstract}
Four experiments test the prediction that feelings of power lead individuals to discount advice received from both experts and novices. Experiment 1 documents a negative relationship between subjective feelings of power and use of advice. Experiments 2 and 3 further show that individuals experiencing neutral and low levels of power weigh advice from experts and experienced advisors more heavily than advice from novices, but individuals experiencing high levels of power discount both novice and expert advice. Experiments 3 and 4 demonstrate that this tendency of individuals experiencing high levels of power to discount advice from experts and novices equally is mediated by feelings of competitiveness (Experiment 3) and confidence (Experiments 3 and 4). Finally, Experiment 4 shows that inducing high power individuals to feel cooperative with their advisors can mitigate this tendency, leading them to weigh expert advice more heavily than advice from novices. Theoretical and practical contributions are discussed.
\end{abstract}

Keywords: advice taking; power; expertise; confidence; competitive mindset; competition 
Power, Competitiveness, and Advice Taking: Why the Powerful Don't Listen

Organizational leaders rarely make critical decisions in isolation. Instead, decision makers more often receive input from advisors from both within and outside their organizations. For example, in the process of making a critical strategic decision, a CEO might receive advice from various members of her board, her top management team, or from a team of consultants. This advice can have varying levels of impact on her ultimate decision. In some circumstances, she may ignore the advice completely; at other times, the advice she receives may influence her decision dramatically. Does the CEO's relative power change her psychological openness to advice? Does the CEO's relative power influence her sensitivity to more or less expert advice?

Research has identified three types of factors that influence individuals' use of advice. First, characteristics of the judgment task affect the extent to which advice influences decisions. Specifically, research has indicated that decision makers weigh advice more heavily when the advice is costly to obtain (Gino, 2008; Patt, Bowles, \& Cash, 2006) and when the task is difficult (Gino \& Moore, 2007; Gino, Shang, \& Croson, 2009). Second, characteristics of the advisor can have an important influence on the extent of advice use. For example, research indicates that advice is weighted more heavily when advisors are relatively more experienced or knowledgeable than the decision makers (Goldsmith \& Fitch, 1997; Feng \& MacGeorge, 2006; Harvey \& Fischer, 1997; Sniezek, Schrah, \& Dalal, 2004; Soll \& Larrick, 2009; Yaniv, 2004; Yaniv \& Kleinberger, 2000; Yaniv \& Milyavsky, 2007) and when the advisors express greater confidence in the quality of their advice (Lawrence \& Warren, 2003; Phillips, 1999; Sniezek \& Buckley, 1995; Sniezek \& Van Swol, 2001; Soll \& Larrick, 2009; Van Swol \& Sniezek, 2005; Yaniv \& Foster, 1997). Finally, aspects of the decision maker's internal states can impact the 
extent of advice-taking. For example, decision makers weigh others' opinions less heavily when they are feeling confident (see Bonaccio \& Dalal, 2006 for a review) or when experiencing incidental emotions that increase feelings of certainty, such as anger (Gino \& Schweitzer, 2008).

In this article, we focus on a type of internal state that is of critical importance in decision making contexts: the decision maker's subjective sense of power. A subjective sense of power refers to the extent to which individuals feel that they can exert influence over the outcomes and experiences of others (Anderson \& Berdahl, 2002; Van Kleef, Oveis, Van der Lowe, LuoKogan, Goetz, \& Keltner, 2008). Prior research on power has proposed that the sense of power has wideranging psychological consequences (Keltner, Gruenfeld, \& Anderson, 2003). For example, recent work has found that the experience of power leads people to act more independently of others (Galinsky, Magee, Gruenfeld, Whitson, \& Liljenquist, 2008) and to resist being influenced by the opinions and perspectives of others (Brinol, Petty, Valle, Rucker, \& Becerra, 2007), thereby reducing the accuracy of their judgments (See, Morrison, Rothman, \& Soll, in press). We suggest that not only does the experience of power lead individuals to be less open to using advice from others, but that power can lead individuals to discount advice even from individuals who have high levels of expertise.

\section{Power and Advice Taking}

One of the most robust findings in the advice taking literature is that people exhibit egocentric advice discounting (Yaniv, 2004; Yaniv \& Kleinberger, 2000) in that they underweight advice from others and over-weight their own opinions (see Bonaccio \& Dalal, 2006 for a review). Scholars have argued that this discounting of advice is particularly likely to occur when decision makers perceive their own opinions to be superior to the opinions and perspectives of others (Krueger, 2003) and consequently feel a high level of confidence in their 
ability to make an accurate judgment independently. This line of reasoning suggests that there will be a greater degree of advice discounting when the decision maker 1) feels optimistic that she will make a good decision, 2) feels that she has the decision under control, and consequently 3) is confident about her own ability in the decision.

Recent research on the psychological effects of power indicates that individuals with a high subjective sense of power are likely to experience each of these three perceptions. First, power has been shown to produce a sense of optimism that leads individuals to perceive risky behaviors as less risky (Anderson \& Galinsky, 2006). Specifically, high power individuals focus on the potential rewards, and ignore the potential downsides, of engaging in risky behaviors. As a result, they expect that, to a disproportionate extent, uncertain events will turn out in their favor. Second, recent research building on the illusion of control (Langer, 1975; Taylor \& Brown, 1988; Thompson, Armstrong, \& Thomas, 1998) has found that power leads individuals to experience an inflated perception of personal control (Fast, Gruenfeld, Sivanathan, \& Galinsky, 2009). Fast et al. (2009) propose that this perception may underlie a broad range of the psychological effects of power, including optimism, high self-esteem, and action-orientation. Third, research has shown that feelings of power increase individuals' levels of confidence in their own opinions and perspectives (Brinol, et al., 2007; See, et al., 2010; Sivanathan \& Galinsky, 2007).

Thus, the subjective experience of power leads people to be optimistic about the outcomes they can produce and to perceive that they have a high level of control over those outcomes; consequently, high power individuals tend to feel overconfident about their abilities. These findings imply that individuals who experience a high level of power are likely to feel that they do not need to rely on advice from others and therefore are likely to significantly discount 
advice. At the same time, individuals with a low level of power are more likely to experience lower levels of optimism, a lower sense of control, and less confidence, leading them to feel a greater need for input from others and therefore to be more willing to take advice. This line of reasoning leads to our first hypothesis:

Hypothesis 1: The experience of power will be associated with lower weighting of advice, such that advice will be weighted less heavily by individuals experiencing a high level of power and more heavily by individuals experiencing a low level of power.

\section{The Role of Advisor Experience and Expertise}

Individuals commonly weigh advice received from experienced and knowledgeable advisors more heavily than advice received from advisors with less experience or expertise (Goldsmith \& Fitch, 1997; Feng \& MacGeorge, 2006; Harvey \& Fischer, 1997; Sniezek, Schrah, \& Dalal, 2004; Yaniv, 2004; Yaniv \& Kleinberger, 2000; Yaniv \& Milyavsky, 2007). Although this research has focused on advice taking in dyadic interactions, related studies have examined the influence of knowledgeable and expert team members and have found similar effects on decision quality in team settings (see Hollenbeck, Ilgen, LePine, Colquitt, \& Hedlund, J., 1998; Hollenbeck, Ilgen, Sego, Hedlund, Major, \& Phillips, 1995; Humphrey, Hollenbeck, Meyer, \& Ilgen, 2002). Research in this area suggests that individuals discount the advice of others because they presume their own judgments to be superior to the judgments of others (Krueger, 2003). As a result, one would expect that when decision makers are presented with evidence that their advisor may have access to superior information or possess more expertise, they would be more inclined to listen to advice.

Therefore, we expect that individuals who experience a low level of power will give more weight to information from expert advisors than from novice advisors. However, we expect 
a different dynamic to emerge for high power decision makers. Specifically, we expect that high power individuals will be insensitive to the level of an advisor's expertise, such that they will discount advice from novices and experts equally. We expect high power individuals to discount novice and expert advice equally because we predict that powerful decision makers will feel competitive with expert advisors. These competitive feelings lead to enhanced confidence, which in turn leads to advice discounting.

To understand why power would lead individuals to feel competitive with expert advisors, it is necessary to consider the nature of power in more detail. An individual's power in a particular social situation refers to the individual's relative ability to control others' outcomes, experiences, or behaviors (Keltner, et al., 2003; Thibaut \& Kelley, 1959). Because power is relative, it is a property of the relations between or among individuals rather than a property of the individual alone (Bacharach \& Lawler, 1980; Kim, Pinkley, \& Fragale, 2005). As such, the power relationship between two individuals can change when aspects of the social situation change. According to power-dependence theory (Blau, 1964; Emerson, 1962), "the power of A over B is equal to and based upon the dependence of B upon A" (Emerson, 1962: 32-33). Thus, if B manages to decrease his or her dependence on A, then A loses power over B. Social dynamics can change power dynamics and lead the powerful to lose power.

Advising is a social process that can have an impact on power dynamics. In an advising context, the power of both the advisor and the decision maker can vary, and one important determinant of the power of the advisor is the advisor's expertise (French \& Raven, 1959). Expertise is a source of power for advisors because advice from experts is likely to be in higher demand than advice from novices. Furthermore, when an advisor has high expertise, the advisor is likely to have information that is valued by the decision maker. In this way, the advisor's 
expertise increases the dependence of the decision maker on the advisor. Thus, expertise shifts the balance of power in the advisor's favor.

On the surface, it may therefore appear that receiving unsolicited advice from an expert would eliminate the negative effect of power on the weighting of advice: In the face of advice from an expert, an otherwise powerful decision maker would feel diminished and accept the advice. However, we expect the dynamic to be more complicated because powerholders do not relinquish their power easily. Previous research has shown that power is associated with an enhanced level of competitiveness (Magee, Galinsky, \& Gruenfeld, 2007). To preserver power, high power individuals often look for traits or characteristics in others that they can construe as justifying their disproportionate amount of power (e.g., Goodwin, Gubin, Fiske, \& Yzerbyt, 2000; Goodwin, Operario, \& Fiske, 1998). Because the desire to maintain power is driven in part by self-enhancement (Pfeffer \& Fong, 2005), an affront to the self-esteem of high power individuals is likely to result in the powerholder experiencing feelings of aggression toward the source of the threat (Fast \& Chen, 2009).

Based on these findings, we expect that, rather than passively accepting a diminished sense of power, individuals who feel a high subjective sense of power will react with feelings of competitiveness when faced with unsolicited advice from experts. This competitiveness represents an intention to establish their superiority to the advisor, which has the effect of refuting the advisor's relative expertise and thus re-affirming their own entitlement to power. Indeed, given the relative and perceptual nature of social power, a shift in the decision maker's feelings of power can occur only if the decision maker chooses to acknowledge the value of the expertise that the advisor holds. Thus, although high power individuals are likely to resist advice from novices because it is low in utility and accuracy, high power individuals resist advice from 
experts for defensive reasons: The expert status of the advisor is a challenge to their own standing.

This line of reasoning is consistent with research indicating that under certain circumstances, advice is experienced as a threat to the decision maker's independence and autonomy. For example, Goldsmith and Fitch (1997) found that in situations with salient power dynamics, such as parent-child relationships, advice is perceived as a threat to the knowledge or ability of the decision maker. Similarly, Koestner and colleagues (1999) found that individuals seeking to maintain independence and power resist the recommendations of others. In addition, Dalal and Bonaccio (2010) found that the motivation to preserve autonomy was enhanced when advice was unsolicited (see also Deelstra, et al., 2003).

On the basis of these findings, we therefore propose that when confronted with an expert advisor, high power individuals will interpret the advice taking context as a competition over "who is right" and will consequently be motivated to out-perform the advisor. In addition, because this competitiveness stems from a motivation to deny the superior knowledge of the advisor, it is likely to be associated with an increase in confidence on the part of the decision maker. Previous research has found that competitive arousal increases decision biases, such as feelings of optimism and illusions of control (Ku, Malhotra, \& Murnighan, 2005; Malhotra, Ku, \& Murnighan, 2008). Similarly, we expect that competitive arousal felt by high power individuals will increase optimism and illusions of control, leading to greater feelings of confidence. Thus, high power individuals' competitive orientation toward expert advisors is likely to lead to a boost in self-confidence related to the decision task, which in turn leads powerholders to decrease the weight that they assign to the advice. 
In summary, we expect that receiving advice from expert but not novice advisors leads high power individuals to experience a state of competitive arousal that enhances their confidence and therefore leads them to discount the advice of experts and novices equally (see Figure 1). The key implication of this line of reasoning is that individuals with neutral or low levels of power will replicate previous findings in which advice from expert advisors is weighted more heavily than advice from novices, but individuals with high levels of power will discount advice from novice and expert advisors alike. We therefore hypothesize the following:

Hypothesis 2: There will be an interaction between decision maker power and advisor expertise, such that individuals with neutral and low levels of power will weigh advice from expert advisors more heavily than advice from novice advisors, whereas individuals experiencing high levels of power will ignore advisor expertise and discount advice from all types of advisors equally.

Consistent with the path model depicted in Figure 1, we further expect a pattern of moderated mediation in which the effect of power on advice taking is mediated by competitiveness and confidence for those who receive advice from an expert, but is not mediated by these variables for those receiving advice from a novice.

Hypothesis 3: For individuals receiving advice from an expert, there will be an indirect mediating path from power to advice taking through competitiveness and confidence; this indirect path will not be significant for individuals receiving advice from a novice.

\section{Overview of Present Research}

We tested our hypotheses in four experimental studies. Following the approach of other scholars in the advice taking literature (e.g., Gino \& Moore, 2007; Yaniv, 2004), the studies employed different estimation tasks over multiple rounds. In the first study, we examined the 
negative effect of power on the degree of advice weighting (Hypothesis 1). The remaining three studies then manipulated the expertise of the advisor by varying the advisor's prior domain experience (Experiment 2) or level of past performance (Experiments 3 and 4). In Experiment 2, we examined our prediction that individuals experiencing low levels of power will weigh advice from experienced advisors more heavily than advice from novices, whereas individuals experiencing high levels of power will discount both types of advice to the same extent (Hypothesis 2). In Experiments 3 and 4, we sought to replicate this interaction focusing on expertise rather than experience as the moderator. Finally, Experiments 3 and 4 also investigated our moderated mediation prediction (Hypothesis 3): In Experiment 3, we examined the roles of competitiveness and confidence in mediating the effect of power and advisor expertise on advice taking; in Experiment 4, we manipulated competitive orientation to further examine the dynamics of the causal chain.

\section{Experiment 1: Power and Advice Taking}

In Experiment 1, we first asked people to engage in an estimation task over multiple rounds. We then manipulated whether participants experienced a high versus low sense of power. We also included a control condition. After the power manipulation, participants engaged in the repeated estimation task once again but this second time they also received advice from others. We expected to find a negative relationship between power and advice weighting (Hypothesis 1), such that people experiencing a high level of power would weigh advice less heavily and individuals experiencing low levels of power would weigh advice more heavily than did participants in the control condition.

\section{Method}


Participants. One hundred seven students (53 female, $M_{\text {age }}=21, S D=2.47$ ) at a private university in the eastern United States participated in the study for pay. Participants received a \$2 show-up fee and had the opportunity to earn an additional $\$ 6$ during the study. Participants were randomly assigned to one of three conditions: high power, low power, and control.

Design and procedure. Participants sat in private computer cubicles. To mitigate potential demand effects, we informed participants that the experiment included two unrelated studies, a Vivid Writing Skills Study and a Weight Estimation Study (two parts).

Weight estimation study (Part I). In Part I of the Weight Estimation Study, participants completed a repeated judgment task. In each of three rounds, participants saw a picture of a person and estimated the person's weight. Participants had an incentive to be accurate; we informed participants that they would receive $\$ 1$ if their estimate fell within 10 pounds of the actual weight of the person in the picture.

Vivid writing skills study. We referred to this segment of the experiment as the Vivid Writing Skills Study. As in prior studies that manipulated power (e.g., Galinsky, Gruenfeld, \& Magee, 2003), participants engaged in a writing task. Based on the experimental condition, participants were asked to recall a situation in which they had power over other people (high power), a situation in which other people had power over them (low power), or their last visit at the grocery store (control), and to write the details of the situation (see Gruenfeld, Inesi, Magee, \& Galinsky, 2008). Consistent with the definition of power as an individual's relative ability to control others' outcomes, experiences, or behaviors, the instructions used in the high $[$ low $]$ power condition read as follows:

Please think about a time when you had power over someone [when someone had power over you]. By power, we mean a situation in which you [this person] controlled the ability of another person or persons [your ability] to get something they [you] wanted, or 
were in a position to evaluate those individuals [you]. Please write 4-5 sentences describing this situation in which you had [did not have] power.

In the control condition, instead, participants received the following instructions:

Please think about the last time you were at the supermarket shopping for yourself. Please write 4-5 sentences describing this situation and one item or product that you purchased for yourself.

Weight estimation study (Part II). After finishing the writing task, participants completed Part II of the Weight Estimation Study. We showed participants the same three pictures they saw in Part I of the Weight Estimation Study, and we again asked participants to estimate the weight of the three different people. This time, however, we provided participants with the estimates that another participant had purportedly made for the same set of photos. For consistency, we kept the three advice values constant across conditions. We explained that these values had been randomly chosen from estimates that participants in a previous study had made when they were assigned to the role of advisor and were paid based upon the accuracy of their estimates. In each round, the advice was of good quality since it fell within $5 \%$ of the true weight of the person in each photograph.

Dependent measure. As in prior advice-taking research, we measured the extent to which participants relied upon advice by using the "weight of advice" (WOA) measure. This measure gauges the extent to which participants revised their estimates in the direction of the advisor's estimate (Harvey \& Fischer, 1997; Yaniv \& Foster, 1997). The WOA ratio is equal to 0 when the advice has no influence on the final estimate, and to 1 when the final estimate is exactly the same as the advice. ${ }^{1}$ We measure WOA with the following fraction:

$$
W O A=\frac{(\text { final estimate }- \text { initial estimate })}{(\text { advice }- \text { initial estimate })}
$$


To maximize the value of advice, participants who are equally well informed should equally weight their own and another person's estimate $($ WOA $=0.5)($ Soll \& Larrick, 2009). We note that prior research has often considered absolute values when computing the WOA measure. For robustness, across all studies, we conducted the analyses using the absolute value approach as well; the nature and significance of our results did not change.

\section{Results}

We conducted analyses that included gender and age as independent variables. We found no main effects or interaction effects for these demographic variables, and we report our findings collapsed across demographic groups. ${ }^{2}$

The mean values of WOA by condition are depicted in Figure 2. A 2-way mixed ANOVA with 1 between-subjects factor (recipient's power: high vs. low) and 1 within-subject factor ( 3 rounds of estimates) found that advice use varied across condition $(F[2,104]=16.95$,

$\left.p<.001, \eta_{p}{ }^{2}=.25\right)$ : Consistent with Hypothesis 1 , advice use in the high power condition was significantly lower than in both the control condition $(p=.034)$ and the low power condition $(p<.001)$; furthermore, advice use in the low power condition was significantly higher than in the control condition $(p<.001)$.

Soll and Larrick (2009) found that the distribution of WOA was trimodal, with peaks at ignoring advice completely $(\mathrm{WOA}=0)$, averaging $(\mathrm{WOA} \approx .5)$, and listening to advice completely $(\mathrm{WOA}=1)$. The strategy of completely ignoring advice is a common one (Soll \& Larrick, 2009) and particularly interesting as an expression of power. Thus, to further explore Hypothesis 1, we examined the frequencies with which advice was ignored completely. Participants in the high power condition ignored the advice $(\mathrm{WOA}=0)$ on $65.6 \%$ of their judgments, which was significantly more than the proportions in the control condition (34.2\%, $p$ 
$<.001$ by two-tailed Fisher exact test $)$ and in the low power condition $(25.7 \%, p<.001$ by twotailed Fisher exact test). Participants in the control condition ignored advice at a marginally higher rate than did participants in the low power condition $(p=.10$ two-tailed Fisher exact test) ${ }^{3}$

\section{Discussion}

These findings support our prediction that power leads individuals to be less receptive to others' advice. Specifically, our analyses demonstrated that advice weight was lowest for individuals in the high power condition, moderate for those in the control condition, and highest for those in the low power condition. High power participants completely ignored advice almost two-thirds of the time - a rate nearly twice that observed in the other conditions. This finding is consistent with our argument that power leads people to feel higher levels of optimism and control that in turn produce feelings of overconfidence and a disinclination to use advice from others. In our second study, we sought to replicate the finding of a main effect of power on advice use and to demonstrate that the tendency for high power individuals to discount advice from others extends even to advice from more experienced individuals.

\section{Experiment 2: Power, Advisor Experience, and Advice Taking}

Experiment 1 demonstrated that individuals primed with high feelings of power were less open to others' advice compared to individuals with low feelings of power or individuals in a control condition. In Experiment 1, participants received advice attributed to a randomly chosen participant from a previous study. This description provided no direct information about the relative ability of the advisor. Experiment 2 tested whether the same results would hold when advice is received from an experienced rather than inexperienced advisor. We expected that there would be an interaction between the participant's level of power and the advisor's experience, 
such that participants experiencing low or neutral levels of power would weigh advice from experienced advisors more heavily than advice from novices. The tendency to give more weight to more able advisors replicates many past results (Goldsmith \& Fitch, 1997; Feng \& MacGeorge, 2006; Harvey \& Fischer, 1997; Sniezek, Schrah, \& Dalal, 2004; Soll \& Larrick, 2009; Yaniv, 2004; Yaniv \& Kleinberger, 2000; Yaniv \& Milyavsky, 2007). However, we expected that participants experiencing a high level of power would preserve their sense of power by discounting advice from experienced advisors and novices equally (Hypothesis 2). Study 2 was designed to test for this interaction.

\section{Method}

Participants. One hundred thirty-two students (62 female, $M_{\text {age }}=21, S D=2.03$ ) at a private university in the eastern United States participated in the study in exchange for a $\$ 2$ show-up fee and the opportunity to earn an additional \$6.

Design and procedure. We randomly assigned participants to one of four experimental conditions from a 2 (Recipient's power: high vs. low) x 2 (Advisor's experience: experienced vs. inexperienced) between-subjects design.

In Experiment 2, we used a different estimation task than the one we used in Experiment 1. Across three rounds, participants viewed a photograph of a jar filled with coins and estimated the amount of money in each jar. In both Part 1 and Part 2 of the estimation task, participants received an additional $\$ 1$ if their estimate fell within 25 cents of the true amount in the jar.

In Experiment 2 we also introduced a new manipulation: advisor's experience.

Participants were told that the advice was a randomly selected estimate from participants in a previous study who were assigned the role of advisor and were paid based on the accuracy of their estimates. In addition, in the experienced-advisor condition, we told participants that their 
advisors engaged in ten practice trials in which they received feedback on the accuracy of their estimates so that they could improve them over time.

Prior to conducting this study, we conducted a pilot study with a non-overlapping sample of participants $(N=86)$. We asked these participants to view the same three photographs and to make estimates that they would offer as advice to future participants. We used the mean value from the pilot study as advice to participants in Experiment 2.

\section{Results}

We conducted a 3-way mixed ANOVA with 2 between-subjects factors (recipient's power: high vs. low; advisor's experience: high vs. low) and 1 within-subject factor (3 rounds of estimates). We found a main effect of power such that low power individuals were more receptive to advice $(\mathrm{Mean} \mathrm{WOA}=0.63, S D=0.38$ ) than were high power individuals (Mean WOA $\left.=0.14, S D=0.31, F[1,128]=69.14, p<.001, \eta_{p}{ }^{2}=.35\right)$. There was no main effect of advisor's experience on advice use $\left(F[1,128]=1.62, p=.21, \eta_{p}{ }^{2}=.01\right)$. However, as predicted in Hypothesis 2, there was a significant interaction between recipient's power and advisor's experience $\left(F[1,128]=3.72, p=.056, \eta_{p}{ }^{2}=.03\right)$. As depicted in Figure 3, low power individuals were more receptive to the advice of experienced advisors than to the advice of inexperienced advisors $\left(F[1,63]=4.25, p<.05, \eta_{p}{ }^{2}=.06\right)$, but high power individuals equally discounted advice independent of the advisor's experience $(p=.61)$.

To further explore Hypothesis 2, we examined the frequencies with which advice was ignored completely depending on advisor experience. When advice came from novices, high power individuals ignored the advice $(\mathrm{WOA}=0)$ on $67.7 \%$ of their judgments compared to $23.3 \%$ of the judgments by low power individuals ( $p<.001$ by two-tailed Fisher exact test). When advice came from experts, high power individuals ignored advice on $75.5 \%$ of their 
judgments compared to just $9.4 \%$ of the judgments by low power individuals $(p<.001$ by twotailed Fisher exact test). ${ }^{4}$ Low power individuals ignored advice significantly more for novice than for expert advisors $(p<.01$ by two-tailed Fisher exact test), but the rate at which high power individuals ignored advice did not differ by advisor expertise $(\mathrm{p}>.10)$. Overall power had the effect of closing judges to advice from all advisors, novice or expert.

\section{Discussion}

These findings are consistent with the results of Experiment 1 and indicate that power leads individuals to be less receptive to others' advice. Furthermore, in support of Hypothesis 2, the findings showed that advice taking by low power individuals was sensitive to an advisor's experience, whereas advice taking by high power individuals was not. Specifically, low power individuals were more receptive to the advice they received when it came from an experienced rather than inexperienced advisor. By contrast, high power individuals heavily discounted advice from any advisor regardless of the advisor's level of experience. In Study 3, we conceptually replicate Study 2 by testing whether advisor expertise measured by past performance produces the same effects as advisor experience. In addition, we explore the role of competitiveness and confidence in mediating the effects of power and advisor ability on advice use.

\section{Experiment 3: Power, Advisor Expertise, and Advice Use}

Our first two studies demonstrated that individuals primed with high power were less open to others' advice compared to individuals with low power, even when advice is received from an experienced rather than inexperienced advisor. The goal of Experiment 3 was twofold. First, we wanted to test whether an advisor's expertise would produce the same results as an advisor's level of experience (providing a second test of Hypothesis 2). Second, we wanted to 
examine the roles of competitiveness and confidence in mediating the relationship between power and advice taking as a test of Hypothesis 3 .

\section{Method}

Participants. One hundred ninety-nine college and graduate students (67 male, $M_{\text {age }}=23$, $S D=7.41)$ from local universities in a city in the Southern United States participated in the study in exchange for a $\$ 4$ show-up fee and the opportunity to earn an additional $\$ 6$.

Design and procedure. We randomly assigned participants to one of six experimental conditions from a 3 (Recipient's power: high vs. low vs. control) x 2 (Advisor's expertise: expert advisor vs. novice advisor) between-subjects design. The study employed the same weight estimation task as in Experiment 1. We manipulated advisor's expertise by giving participants information about the advisor's performance (in terms of accuracy) in a prior session of the same study. In the expert-advisor condition, we told participants that the estimates were those of an advisor who was among the best performers in a previous session (specifically, in the top 5\%). In the novice-advisor condition, we told participants that the estimates were those of an advisor who was among the average performers in a previous session (specifically, in the $50^{\text {th }}$ percentile). We used the same power manipulation employed in Experiments 1 and 2.

After the second part of the Estimation Study we included a questionnaire with measures of state competitiveness and confidence. We randomized the order in which these questions were presented to participants. The questionnaire also included manipulation checks and demographic questions related to age and gender.

Measures. Unless otherwise indicated, participants answered the questions with our measures by indicating their level of agreement on a 7-point scale (1=strongly disagree, $7=$ strongly agree $)$. 
Competitiveness. To measure competitiveness, we modified the competitiveness index scale suggested by Houston and colleagues (see Houston, Farese, \& La Du, 1992; Smither \& Houston, 1992) so that we could capture state competitive mindset. The scale included the following items: 1) Right now, I think that competing against an opponent would be enjoyable and 2) Right now, I think that keeping score is important when playing games. The two items were correlated at $r=.73, \mathrm{p}<.001$, which corresponds to $\alpha=.84(M=4.95, S D=1.42)$.

Confidence. We measured confidence by asking participants to indicate their level of agreement on a 7-point scale with the following three items: 1) I am very certain about the accuracy of my judgments, 2) I feel confident I performed well on this task, and 3) I have no doubt my estimates are close to the true values $(\alpha=.89)(M=4.08, S D=1.33)$. The measures of confidence and competitiveness were positively correlated $(r=.30, p<.001)$.

\section{Results}

Manipulation checks. We confirmed that all participants correctly recalled the information we provided regarding the advisor's level of expertise. Specifically, participants in the expert advisor condition were able to indicate that their advisor was in the top 5\% of performers, and participants in the novice advisor condition were able to indicate that their advisor was in the $50^{\text {th }}$ percentile.

To test for the effect of the power manipulation, we asked participants to think back to the experience that they had written about at the beginning of the study, and to indicate the amount of power they personally felt in that experience using a 7-point scale (from 1=very little to $7=a$ great deal). We used their answers to this question as the dependent variable in a 3 (recipient's power) x 2 (advisor's expertise) between-subjects ANOVA. This analysis revealed only a significant effect of power in the expected direction $\left(F[2,193]=62.66, p<.001, \eta_{p}{ }^{2}=.39\right)$ : 
Participants reported higher ratings in the high power condition $(M=5.27, S D=1.01)$ compared to both the control condition $(M=4.73, S D=1.43 ; p<.04)$ and the low power condition $(M=2.68$, $S D=1.60 ; p<.001)$, indicating that our manipulation of power was effective. The ratings of perceived power were significantly lower in the low power condition than in the control condition $(p<.001)$.

Advice-taking. We conducted a 3-way mixed ANOVA with 2 between-subject variables (recipient's power: high, low, or neutral; advisor's expertise: high vs. low) and 1 within-subject variable (3 rounds of estimates). We found a significant effect for power $(F[2,179]=18.41$, $\left.p<.001, \eta_{p}{ }^{2}=.17\right)$ and a significant effect for advisor's expertise $(F[1,179]=17.27, p<.001$, $\eta_{p}{ }^{2}=.09$ ). More interestingly, as depicted in Figure 4, the interaction between recipient's power and advisor's expertise was also significant $\left(F[2,179]=5.86, p<.01, \eta_{p}{ }^{2}=.06\right)$. Low power individuals were more receptive to the advice of expert advisors than to that of novice advisors $\left(F[1,179]=27.37, p<.001, \eta_{p}{ }^{2}=.13\right)$. Participants in the control condition were also more receptive to the advice of expert advisors than to that of novice advisors, but this difference only reached marginal significance $\left(F[1,179]=2.72, p=.10, \eta_{p}{ }^{2}=.02\right)$. High power individuals, instead, equally discounted advice independent of the advisor's expertise $(p=.65)$. Thus, Hypothesis 2 was again supported.

To further explore Hypothesis 2, we examined the frequencies with which advice was ignored completely depending on advisor expertise. When advice came from novices, high power individuals ignored the advice $(\mathrm{WOA}=0)$ on $53.3 \%$ of their judgments compared to $31.0 \%$ of the judgments by low power individuals ( $p<.001$ by two-tailed Fisher exact test). When advice came from experts, high power individuals ignored advice on $56.0 \%$ of their judgments compared to just $6.7 \%$ of the judgments by low power individuals $(p<.001$ by two- 
tailed Fisher exact test). ${ }^{5}$ Low power individuals ignored advice from novices more than from experts $(\mathrm{p}<.001)$; high power individuals did not differ across experts and novices $(\mathrm{p}>.10)$. As in Study 2, power had the effect of closing judges to advice from all advisors, novice or expert.

Explaining the link between power and advice taking. In order to test for support for the path model depicted in Figure 1, we focused only on the high power and the low power conditions since we were interested in the differences produced by these two levels of power on advice use. We followed the path-analysis procedures recommended by Edwards and Lambert (2007), which are implemented by running regressions on the mediators and the dependent variable and using the results of these regressions to generate a reduced form equation (i.e., that includes only exogenous variables as predictors), which is used to compute simple paths that constitute the indirect effect of the independent variable at different levels of the moderator variable. Below, we explain the results from the three constituent regressions in turn, and we then present the results for the indirect effects computed using the bootstrap procedure.

We used hierarchical linear regression and began by regressing our measure of competitiveness on dummy variables for power (high power $=1$; low power $=0$ ) and advisor's expertise $($ expert $=1$; novice $=0)$ in the first step and found a significant effect of power $(b=.66$, $t=2.74, p<.01)$. We then entered the interaction on the second step. Inclusion of the interaction term led to a significant increase in variance explained in the second step (from $R^{2}=.06$ to $\left.R^{2}=.09 ; p=.02\right)(b=1.16, t=2.37, p<.05)$. Contrast analyses revealed that there was a significant effect of power on competitiveness within the expert advisor condition (low power: $M=4.32$, $S D=1.23$; high power: $\left.M=5.70, S D=1.19 ; F[1,131]=12.78, p<.001, \eta_{p}{ }^{2}=.09\right)$, but there was no simple effect of power within the novice advisor condition (low power: $M=4.82, S D=1.50$; high power: $\left.M=5.04, S D=1.37 ; F[1,131]=.55, p=.46, \eta_{p}{ }^{2}=.004\right)$. Contrast analyses further revealed 
that there was a marginally significant simple effect of advisor expertise within the high power condition (novice: $M=5.04, S D=1.37$; expert: $M=5.70, S D=1.19 ; F[1,131]=3.38, p=.068$, $\eta_{p}{ }^{2}=.03$ ), but there was no simple effect of advisor within the low power condition (novice: $M=4.82, S D=1.50 ;$ expert: $\left.M=4.32, S D=1.23 ; F[1,131]=2.24, p=.14, \eta_{p}{ }^{2}=.02\right)$. These findings support our contention that the experience of power leads decision makers to experience feelings of competitiveness when they encounter an expert advisor. These findings also indicate support for the first stage of our proposed path model (Figure 1).

Next, we tested our prediction for the second stage of our path model, in which we expected that there would be a main effect of competitiveness on confidence. To do so, we again used hierarchical linear regression. In the first step, we entered the dummy variable for power and found a significant effect of power on confidence $(b=.54, t=2.38, p<.05)$. On the second step we entered our measure of competitiveness (centered) and found a significant effect of competitiveness on confidence $(b=.36, t=3.19, p<.01)$. In the second step, the effect of power was no longer significant, indicating that the measure of competitiveness fully mediated the effect of power on confidence. We note that including the measure of competitiveness significantly improved the variance explained (from $r^{2}=.04$ to $r^{2}=.11, F(1,132)=10.17, p<.01$ ). These results support the second stage of our path model.

To explore the third stage of our path model, in which we expected that there would be an effect of confidence on WOA, we again used hierarchical linear regression. In the first step, we entered the dummy variable for power and found a significant effect of power on WOA $(b=-.23$, $t=-4.35, p<.001)$. In the second step, we entered our measure of confidence (centered), which was significant $(b=-.10, t=-4.09, p<.001)$. We note that including the measure of confidence decreased the effect of power $(b=-.19, t=-3.35, p=.001)$ and significantly improved the variance 
explained (from $r^{2}=.12$ to $r^{2}=.22, F(1,132)=16.78, p<.001$ ). In addition, we wanted to confirm that our measure of confidence mediated the effect of competitiveness on WOA. To do so, we again used hierarchical linear regression. In the first step, we entered our measure of competitiveness (centered) and found a significant effect of competitiveness (centered) on WOA ( $b=-.06, t=-2.09, p<.04)$. In the second step, we entered our measure of confidence (centered), which was significant $(b=-.11, t=-4.24, p<.001)$. We note that including the measure of confidence eliminated the effect of competitiveness on WOA $(b=-.02, t=-0.84, p=.40)$ and significantly improved the variance explained (from $r^{2}=.03$ to $r^{2}=.15, F(1,132)=17.98, p<.001$ ). These results support the third stage of our path model.

We then used the results of these three regressions to test whether the indirect effect of power through competitiveness and confidence was moderated by advisor's expertise, as depicted in our path model (Figure 1). Specifically, we used a bootstrap procedure on the regressions of competitiveness, confidence, and WOA in order to construct bias-corrected confidence intervals based on 1,000 random samples with replacement from the full sample, as recommended by Edwards and Lambert (2007; see also MacKinnon, Fairchild, \& Fritz, 2007; Shrout \& Bolger, 2002). The analysis indicated that the indirect effect of power on WOA through competitiveness and confidence was significant for those in the expert advisor condition (bias-corrected 95\% confidence interval: -.11 to -.02) but not for those in the novice advisor condition (bias-corrected 95\% confidence interval: -.04 to .01) (see Table 1). Thus, Hypothesis 3 was supported. In addition, we note that the direct effect of power on WOA was diminished but remained significant regardless of the advisor's level of expertise, indicating that the mediation was partial. 
Finally, our moderated mediation prediction entails an expectation that the causal chain from competitiveness to confidence to WOA should be significant when high power people receive advice from experts but should not be significant when high power people receive advice from novices. We tested this aspect of the expected causal chain using the bootstrap procedure on only our high power participants. The analysis confirmed a significant indirect effect from competitiveness to WOA through confidence when high power participants received advice from an expert (bias-corrected $95 \%$ confidence interval: -.31 to -.05), and the indirect effect was not significant when the high power participants received advice from a novice (bias-corrected $95 \%$ confidence interval: -.09 to .03). Thus, the causal chain from competition to confidence to WOA is significant only among high power participants receiving advice from experts. This analysis provides additional support for Hypothesis 3.

\section{Discussion}

The results of our third study are consistent with those of Experiments 1 and 2.

Participants were more receptive to the advice of others when they experienced low power than when they experienced high power. Our results also show that advisor expertise only influences the extent of advice taking for participants experiencing low power; participants experiencing high power did not adjust their weight of advice according to the advisor's expertise. In addition, our results further demonstrate that the effect of power on advice use is mediated by competitiveness and confidence for those receiving advice from experts. Specifically, when individuals received advice from experts, power significantly increased feelings of competitiveness, which in turn increased confidence and reduced advice-taking. However, high and low power individuals did not differ significantly in competitiveness or confidence when 
facing novice advisors (and the indirect effect for those receiving advice from novices was not significant). Therefore, our path model based on Hypothesis 3 was supported.

\section{Experiment 4: Power, Competitiveness, and Advice Use}

The results of Experiment 3 indicated that high power people feel competitive when exposed to advice from experts and that these feelings of competition lead them to inflate their confidence and underweight experts' advice. Thus, one important implication of Study 3 is that when powerful people feel cooperative with their advisors, rather than competitive, they are likely to behave similarly to their lower power counterparts and weigh the advice of experts more heavily than advice from novices. In order to explore this possibility, and to examine our proposed causal mechanism in more detail, we conducted an additional study in which we exposed all participants to a high power prime and then manipulated both advisor expertise and feelings of competition vs. cooperation with the advisor.

Thus, Experiment 4 involved a 2 (advisor expertise: expert vs. novice) x 2 (participant mindset: competitive vs. cooperative) between-subjects design, in which self-confidence was measured and all participants received the high power writing task. We expected an interaction between advisor expertise and participant mindset, such that in the competitive condition, participants (all of whom were high power) would discount advice from novices and experts equally (as in Experiments 2 and 3), but that in the cooperation condition, participants would weigh the advice of experts more heavily than advice from novices. Consistent with Hypothesis 3 and the findings from Experiment 3, we expected that this interaction would be mediated by feelings of confidence. 


\section{Method}

Participants. Two-hundred and two adults (56\% female, $\left.M_{\text {age }}=33.62, S D=11.47\right)$ participated in the study for pay. Participants received a $\$ 2$ show-up fee and had the opportunity to earn an additional $\$ 6$ during the study.

Design and procedure. Participants completed the study online, at their own computer. To mitigate potential demand effects, we informed participants that the experiment included three unrelated studies: a Vivid Writing Skills Study, a Weight Estimation Study (two parts), and a final task described as either "Cooperative Alliance Task" or "Strategic Competition Task," depending on condition. For the Vivid Writing Skills task, all participants received the high power version of the task. The study employed the same weight estimation task as in Experiments 1 and 3, and the same manipulation of advisor's expertise used in Experiment 3. Before presenting the advisor's estimates, however, we first described the fourth part of the study to participants. Participants were told that Part 4 of the study would require them either to work cooperatively with their advisor (cooperation condition) or to engage in a game in which they would compete with their advisor (competition condition). We also reinforced the strength of the manipulation by referring to the tasks with different titles (Epley, Caruso, \& Bazerman, 2006). Specifically, the task was entitled "Part 4: Cooperative Alliance Task" in the cooperative condition and "Part 4: Strategic Competition Task" in the competitive condition.

We then asked half of our participants to respond to a few brief questions to assess their confidence in their original estimates. The other half were not asked to respond to these questions until after they received their advisor's advice and reported their own final estimates of the weights. This approach allowed us to test for mediation by assessing whether feelings of confidence arise before, or only after, the participants receive advice and report their final 
estimates. We assessed self-confidence by asking participants to indicate their agreement with the following statements using a 7-point scale (scale: 1=strongly disagree, $7=$ strongly agree): 1) I am very certain about the accuracy of my judgments; 2) I feel confident I performed well on this task; and 3) I have no doubt my estimates are close to the true values $(\alpha=.92)$.

Next, we presented the advisors' estimates and asked the participants to report their own final estimates. Once again, we kept the three advice values constant across conditions. After participants indicated their final estimates of the weights, we included a questionnaire. The questionnaire included measures of confidence (for those who did not respond to those items before their final estimates), as well as manipulation checks and demographic questions related to age and gender. We randomized the order in which these questions were presented to participants.

\section{Results}

Manipulation checks: advisor's expertise. We confirmed that all participants correctly recalled the information we provided regarding the advisor's level of expertise. Specifically, participants in the expert advisor condition were able to indicate that their advisor was in the top $5 \%$ of performers, and participants in the novice advisor condition were able to indicate that their advisor was in the $50^{\text {th }}$ percentile. In addition, participants indicated how expert they believed their advisor to be on a 7-point scale (1=not at all, 7=very much). A 2 (advisor's expertise: high vs. low) X 2 (task description: competition vs. cooperation) ANOVA revealed a main effect for advisor's expertise, $F(1,198)=111, p<.001, \eta_{p}{ }^{2}=.36$ : Participants reported higher ratings in the expert advisor condition $(M=5.33, S D=1.01)$ than in the novice advisor condition $(M=3.76$, $S D=1.10$ ), indicating that our manipulation of advisor's expertise was effective. Both the main effect of task description and the interaction were not significant (both $F_{\mathrm{s}}<1$ ). 
Manipulation checks: competition toward advisor. We also confirmed that all participants correctly recalled the information we provided regarding whether they would be competing or cooperating with their advisor in the final task. Specifically, participants in the competition condition were able to indicate that they would compete with their advisor, and participants in the cooperation condition were able to indicate that they would cooperate with their advisor. In addition, participants indicated how cooperative or competitive they felt toward their advisor $(1=$ very cooperative, $7=$ very competitive). A 2 (advisor's expertise) X 2 (task description) ANOVA revealed a main effect for task description, $F(1,198)=48.22, p<.001$, $\eta_{p}{ }^{2}=.20$ : Participants reported higher ratings of competitiveness in the competition condition $(M=4.91, S D=1.64)$ than in the cooperation condition $(M=3.19, S D=1.86)$, indicating that our manipulation of competition toward the advisor was effective. Both the main effect of advisor's expertise and the interaction were not significant (both $F_{\mathrm{S}}<1$ ).

Manipulation checks: power. We also included a question regarding participants' experience of power. Participants were asked to think back to the experience that they wrote about at the beginning of the study, and to indicate the amount of power they personally felt in that experience on a 7-point scale ( $1=$ very little to $7=$ a great deal). The average rating was 5.47 $(S D=1.25)$. As expected given that our manipulations were introduced after the power induction, this rating was not affected by our manipulations. We then proceeded to test our hypotheses.

Advice-taking. We conducted a 3-way mixed ANOVA with two between-subject variables (advisor's expertise and task description) and one within-subject variable (3 rounds of estimates). We found a significant effect for advisor's expertise $(F[1,190]=14.91, p<.001$, $\left.\eta_{p}{ }^{2}=.07\right)$ and a significant effect for task description $\left(F[1,190]=11.46, p=.001, \eta_{p}{ }^{2}=.06\right)$. More interestingly, as depicted in Figure 6, the interaction between the two manipulations was also 
significant $\left(F[1,190]=5.67, p<.02, \eta_{p}{ }^{2}=.03\right)$. As was true for subjects experiencing high power in Experiments 2 and 3, participants in Experiment 4 who expected to compete with their advisor discounted the advice of novice and expert advisors equally $(F[1,190]=1.06, p=.30)$. However, participants who expected to cooperate with their advisor were more receptive to advice from experts than from novices $\left(F[1,190]=20.10, p<.001, \eta_{p}{ }^{2}=.10\right)$. Indeed, participants who received advice from experts with whom they expected to cooperate exhibited the highest level of WOA of the four cells (all $p$ 's $<.001$ ).

We also examined the frequencies with which advice was ignored completely. In the competition condition, participants ignored advice $(\mathrm{WOA}=0)$ from novices on $37.0 \%$ of their judgments and ignored advice from experts on $38.7 \%$ of their judgments. In the cooperation condition, participants ignored advice from novices on $36 \%$ of their judgments and ignored advice from experts on $15.1 \%$ of their judgments ( $p<.001$ by two-tailed Fisher exact test) ${ }^{6}$

Compared to the high power conditions in the previous studies, Experiment 4 revealed a lower rate of completely ignoring advice $(\mathrm{WOA}=0)$. Although we do not have a definitive explanation for this pattern, we note that the population was substantially different: Experiment 4 involved an online sample of adults and not a college-based population.

Confidence. We then examined whether our manipulations affected participants'selfreported level of confidence. A 2 (advisor's expertise) X 2 (competition) ANOVA revealed a significant effect for advisor's expertise $\left(F[1,198]=5.05, p<.03, \eta_{p}{ }^{2}=.03\right)$ and a significant effect for task description $\left(F[1,198]=8.79, p<.01, \eta_{p}{ }^{2}=.04\right)$. More interestingly, the interaction between the two manipulations was also significant $\left(F[1,198]=6.11, p<.02, \eta_{p}{ }^{2}=.03\right)$. Participants who expected to compete with their advisor reported feeling equally confident independent of whether the advisor was a novice or an expert $\left(M_{\text {novice }}=5.07, S D=1.19\right.$ vs. $M_{\text {expert }}=5.11, S D=1.40$, 
$F[1,198]=0.02, p=.88)$. However, participants who expected to cooperate with their advisor reported feeling less confident when the advisor was an expert than when the advisor was a novice ( $M_{\text {expert }}=4.08, S D=1.31$ vs. $M_{\text {novice }}=4.97, S D=1.46, F[1,198]=11.35, p=.001, \eta_{p}{ }^{2}=.05$ ). Indeed, participants who received advice from experts with whom they expected to cooperate exhibited the lowest levels of confidence of the four cells (all $p$ 's $=<.001$ ). Controlling for the timing of these variables in our analyses did not substantively affect the results.

First-stage moderated mediation model. We conducted additional analyses to examine whether self-reported confidence would explain the moderating effect of competition on the relationship between advisor's expertise and advice taking for high power individuals. We expected that competition would moderate the effect of advisor's expertise on self-reported confidence, which would directly predict higher levels of advice taking, constituting a first-stage moderation model (Edwards \& Lambert, 2007). To test for this effect, we used hierarchical linear regression in which we entered dummy variables for advisor expertise (expert $=1$; novice $=0$ ) and competition (competitive orientation $=1$; cooperative orientation $=0$ ) in the first step, the interaction between the two in the second step, and our measure of self-reported confidence in the third step. When the measure of confidence was included, the interaction between advisor's expertise and competition became non-significant $(b=-0.05, t=-0.72, p=.47)$, whereas self-reported confidence was a significant, negative predictor of advice taking $(b=-.12, t=-9.36$, $p<.001)$. In addition, we used the bootstrap procedure recommended by Edwards and Lambert (2007) to assess the indirect effect of advisor expertise on WOA through confidence for individuals in the competition vs. cooperation conditions. Consistent with our causal model and with the finding reported above that there is no effect of advisor expertise on WOA for individuals in the competition condition, we expected that there would be an indirect effect of 
expertise on WOA mediated by confidence for those in the cooperation condition but not among those in the competition condition. The analysis indicated that the indirect effect was significant for those in the cooperation condition (bias-corrected $95 \%$ confidence interval: 0.04 to 0.23 ) but not for those in the competition condition (bias-corrected $95 \%$ confidence interval: -0.10 to 0.09 ) (see Table 2).

\section{Discussion}

The results of our fourth study replicate the findings of Experiments 2 and 3 with respect to high power individuals and provide further support for our predicted causal mechanism. Specifically, Experiment 4 demonstrated that high power participants discount advice from experts and novices equally but that when high power participants are made to feel cooperative with their advisors, they weigh advice from experts more heavily. Furthermore, the findings indicate that high power participants who feel competitive with their expert advisors report increased feelings of confidence in their own judgments relative to high power participants who feel cooperative with experts. These feelings of confidence mediate the interactive effect of advisor expertise and competitive vs. cooperative orientation on WOA. Thus, the findings of Experiment 4 provide further support for our hypothesized causal model.

In sum, the competitive feelings created in our manipulation reinforced the default mindset of high power decision makers - for them, taking advice from an expert would diminish their standing and they responded by reasserting their own competence. In contrast, a cooperative mindset led our high power participants to behave more like the low power or control participants from our previous experiments, exhibiting less confidence in their own judgments and accepting advice more readily from experts. 


\section{General Discussion}

The four experiments presented here demonstrate that feelings of power lead individuals to decrease their use of advice from others and to discount advice from experts and novices equivalently. In Experiment 1, the findings confirmed that there is a negative relationship between subjective feelings of power and use of advice from others. In addition, Experiments 2, 3 , and 4 demonstrated that individuals experiencing high levels of power not only discounted advice from novice advisors, but also discounted advice from expert advisors. In contrast, individuals experiencing neutral and low levels of power in Experiments 2 and 3 exhibited behavior that was consistent with previous research findings: They weighed advice from experts and experienced advisors more heavily than advice from novices. Finally, Experiments 3 and 4 provided evidence supporting our causal mechanism. Experiment 3 found that high power individuals felt increased competitiveness and confidence when paired with an expert advisor. A moderated mediation analysis demonstrated that the tendency of high power individuals to discount advice from experts and novices equivalently is mediated by feelings of competitiveness and confidence. In Experiment 4, we manipulated competitive vs. cooperative orientation among high power individuals and demonstrated that the boost in confidence and consequent discounting of advice that high power decision makers exhibit when receiving advice from experts can be eliminated if the decision maker can be induced to feel cooperative, rather than competitive, with the advisor.

\section{Theoretical Contributions}

We highlight four main theoretical contributions of this research, two with respect to research on advice and two with respect to research on power. First, the findings from these studies contribute to the ongoing research indicating that the decision maker's internal states can 
have important influences on the extent of advice taking (e.g., Cooper, 1991; Gino \& Schweitzer, 2008). Previous work in this area has focused primarily on the influence of decision makers' emotional states (Gino \& Schweitzer, 2008; Lerner \& Tiedens, 2006). Our work extends this line of research by showing that the decision maker's subjective sense of power is an important factor impacting the extent of advice use (see also See, et al., 2010). Second, our studies also provide insight about when and why this happens. Advice taking by high power individuals is less sensitive to advisor expertise than is advice taking by low power individuals. This happens because high power individuals experience greater competitiveness and confidence when they confront expert advisors, and these internal states mediate the link between power and advice use.

The research presented here also contributes in two key ways to research on the psychological effects of power. First, our findings from Experiment 3 extend previous research on the relationship between power and competitiveness. Specifically, prior studies have found that power increases competitive behavior in competitive social contexts, such as negotiations (Magee, Galinsky, \& Gruenfeld, 2007). Our findings provide further support for this dynamic but also extend previous findings by highlighting that high power individuals are more likely to perceive situations as competitive when their status, power, or influence are threatened (e.g., when confronted with someone with greater expertise). Second, our findings in Experiments 3 and 4 also complement previous research on power and overconfidence (e.g., See et al., 2010; Sivanathan \& Galinsky, 2007) by demonstrating that the effect of power on confidence may at times be mediated by competitiveness. 


\section{Implications for Practice}

In recent years, there has been increasing interest in the fact that averaging judgments across people increases the accuracy of judgments (Clemen, 1989), which has been termed the "wisdom of crowds" (Surowiecki, 2004). An important insight from past research is that there are diminishing marginal returns to crowd size. For a given judgment, the first piece of advice is far more valuable than the second (or third, or fourth) piece of advice because it doubles the sample size (Hogarth, 1978). Research has shown, however, the people misunderstand the benefits of combining the estimates of two people (Larrick \& Soll, 2006), and, in revising their own judgments, often ignore advice from others $(\mathrm{WOA}=0)$, making their final estimates less accurate than if they had given equal weight to advice $($ WOA = .5) (Soll \& Larrick, 2009). Although there are circumstances when ignoring advice is an effective strategy (for example, when the advisor has substantially less expertise than the advisee), it is a demonstrably inferior strategy to averaging when a judge and advisor are equally expert (Soll \& Larrick, 2009). Under any reasonable assumption about differences in expertise, the high power individuals in Experiments 3 and 4 should be integrating the judgments of a "top 5\% expert" with their own judgments rather than ignoring the expert's judgments.

The tendency for power to reduce the use of advice suggests that organizational leaders should take steps to mitigate the negative effects of power. One way to do so may be to attempt to prevent subjective feelings of power from emerging in the first place. To that end, leaders may attempt to design work roles and responsibilities in ways that equalize power relations across organizational actors and promote non-hierarchical cultures. Alternatively, leaders could work to push decision making power as much as possible to the lower levels of organizational hierarchy. There is a general logic for decentralizing decisions because it allows people with the best 
information to make key organizational decisions. A secondary benefit of decentralization may be psychological: Decisions will be made by people who feel less powerful and are therefore more open to advice from others.

In addition, organizational leaders could also take steps to minimize the likelihood of high power individuals experiencing feelings of competitiveness with advisors. This goal might be achieved by structuring tasks such that high power individuals are induced to feel a cooperative orientation to their advisors, as in Experiment 4. This goal may also be achieved by taking action to provide decision makers with feelings of security about their status and position so that exposure to experts is experienced as less threatening. This type of reassurance could occur by training advisors to affirm the knowledge and experience of the decision maker as a step to making their advice more impactful. At the same time, the goal of diminishing feelings of competitiveness could also be accomplished by choosing decision makers who are relatively more self-assured and who feel the effects of competitive arousal less acutely (Malhotra, Ku, \& Murnighan, 2008).

We conclude by noting that although listening to advice is an effective way to form more accurate judgments, there is a potential social cost: Relying on others can be perceived as a sign of incompetence or uncertainty (Lee, 1997; Westphal, 1999). Those who hold power and want to maintain it may in fact be acting appropriately to preserve their social dominance. To combat the potential social costs of taking advice, organizations need to create cultures in which organizational members are encouraged to share information and leaders are rewarded for seeking and integrating the perspectives of others. 


\section{Limitations and Future Directions}

There are multiple avenues of future research that could explore the limitations and boundary conditions of our findings. Specifically, we focus on the effects of power on the use of unsolicited advice. However, it would be interesting to explore whether power also has similar effects on the likelihood that advice will be sought in the first place: Are individuals who experience an enhanced feeling of power also less likely to seek advice? If such an effect exists, is it also mediated by competiveness and confidence? Furthermore, once advice has been solicited, would the effect of power on weight of advice persist? We suspect that it would not: When a high power person solicits advice from another, the very act of soliciting advice can be viewed as an affirmation of the decision maker's high-power status, and it is likely that this affirmation could minimize the feelings of competitiveness that would otherwise emerge due to status threat.

In addition, our manipulation of power focused primarily on a particular type of power. French and Raven (1959) distinguish among reward, coercive, expert, legitimate, and referent forms of power. Our manipulation of power ("By power, we mean a situation in which you controlled the ability of another person or persons to get something they wanted, or were in a position to evaluate those individuals") focused on reward power, which refers to an actor's ability to control the rewards others receive, and coercive power, which refers to an actor's ability to punish others. We suspect that the effect of power on expert and novice advice use may vary across bases of power. If the decision maker's power is based on expertise, then the threat of advice from experts may be particularly high, leading to an even greater tendency to discount advice. However, if the decision maker's power is based on legitimate (power based on others' perceptions that the decision maker has lawful authority) or referent power (power based on 
attraction and identification), then expert advice may represent less of a status threat, and perhaps the effects demonstrated in our studies would be mitigated.

The nature of the power manipulation used in our studies also prompts us to consider another potential boundary condition of these effects. Specifically, we used a writing prime to elicit individuals' subjective feelings of power unrelated to the experimental task. This approach raises the question of whether the competitiveness that our high power individuals felt in response to expert advice would necessarily emerge among individuals who have achieved authority positions in organizations. Certainly individuals in positions of authority are frequently primed with power by cues in their environments, such as the deferential behavior of others and the high status perks associated with their offices. However, might individuals in positions of authority become accustomed or habituated to these cues, such that these cues no longer elicit the subjective feelings of power that were the focus of our experimental manipulations? If so, we would not expect our findings to generalize broadly to every decision made by an individual in a position of power; instead, we would only expect that our findings would generalize in those circumstances in which the powerful individual experiences a subjective awareness or feeling of power. Similarly, it is possible that the writing prime approach to the manipulation of power elicited rather tenuous feelings of power, making our participants particularly susceptible to feelings of threat when confronted with an expert. This observation suggests that our results would be less robust among individuals who feel highly secure in their position of power or whose power bases are quite solidified; future research should investigate these possibilities.

Other interesting avenues of inquiry remain as well. For example, we did not examine the effect of power on judgment quality: Does the tendency for high power individuals to discount advice from experts lead to a decrease in judgment quality? We expect that it does, but future 
research should explore this issue. It would also be interesting to explore whether the experience of power makes people more open to advice under some circumstances. Previous research indicates that high power individuals are strategic in their interactions, such that they allocate attention to those whom they perceive as instrumental to their goals but ignore individuals whom they perceive as less useful in their goal pursuits (e.g., Gruenfeld, Inesi, Magee, \& Galinsky, 2008; Overbeck \& Park, 2006). This line of reasoning suggests that high power individuals may be more willing to seek and use advice from individuals who have expertise that is clearly instrumental to their goal pursuits (Fitzsimons \& Shah, 2009). Finally, it would be interesting to explore the role of feelings of power in prompting advice provision: Are high power individuals more likely to give advice than are individuals with lower levels of power?

\section{Conclusions}

Other people are a source of broader perspectives and differing opinions. Acquiring this information is arguably the easiest way to improve one's decisions (Larrick, 2009). But do people listen to others? Individuals with formal positions of authority are generally granted broad decision-making authority and would benefit from listening to others; however, formal authority itself can create feelings of power, competitiveness, and confidence that inhibit advice taking. The studies presented here represent a first step toward a better understanding of a paradox of power - greater decision rights are often coupled with a power-induced neglect of the judgments of others. The findings have important theoretical implications for advice taking research and for research on the psychological effects of power, and they also have important practical implications for mitigating the negative effect of power on advice taking. 


\section{References}

Anderson, C., \& Berdahl, J. L. (2002). The experience of power: Examining the effects of power on approach and inhibition tendencies. Journal of Personality and Social Psychology, 83, 1362-1377.

Anderson, C., \& Galinsky, A. D. (2006). Power, optimism, and risk taking. European Journal of Social Psychology, 36, 511-536.

Bacharach, S. B., \& Lawler, E. J. (1980). Power and politics in organizations. San Francisco: Jossey-Bass.

Blau, P. M. (1964). Exchange and power in social life ( $5^{\text {th }}$ Edition). New Brunswick, NJ: Transaction.

Bonaccio, S., \& Dalal, R. S. (2006). Advice taking and advice giving in decision making: An integrative review of the literature. Organizational Behavior and Human Decision Processes, 101, 127-151.

Brinol, P., Petty, R. E., Valle, C., Rucker, D. D., \& Becerra, A. (2007). The effects of message recipients' power before and after persuasion: A self-validation analysis. Journal of Personality and Social Psychology, 93, 1040-1053.

Clemen, R. T. (1989). Combining forecasts. International Journal of Forecasting, 5, 559-583.

Cooper, R. S. (1991). Information processing in the judge-adviser system of group decisionmaking. Unpublished master's thesis, University of Illinois, Urbana-Champaign.

Dalal, R. S., \& Bonaccio, S. (2010). What types of advice do decision makers prefer? Organizational Behavior and Human Decision Processes, 112, 11-23. 
Deelstra, J. T., Peters, M. C. W., Schaufeli, W. B., Stroebe, W., Zijilstra, F. R. H., \& van Doornen, L. P. (2003). Receiving instrumental support at work: When help is not welcome. Journal of Applied Psychology, 88, 324-331

Edwards, J. R., \& Lambert, L. S. (2007). Methods for integrating moderation and mediation: A general analytical framework using moderated path analysis. Psychological Methods, 12, $1-22$.

Emerson, R. M. (1962). Power-dependence relations. American Sociological Review, 27, 31-40.

Epley, N., Caruso, E.M., \& Bazerman, M. H. (2006). When perspective taking increases taking: Reactive Egoism in social interaction. Journal of Personality and Social Psychology, 91, 872-889.

Fast, N. J., \& Chen, S. (2009). When the boss feels inadequate: Power, incompetence, and aggression. Psychological Science, 20, 1406-1413.

Fast, N. J., Gruenfeld, D. H., Sivanathan, N., \& Galinsky, A. D. (2009). Illusory control: A generative force behind power's far-reaching effects. Psychological Science, 20, 502508.

Feng, B., \& MacGeorge, E. L. (2006). Predicting receptiveness to advice: Characteristics of the problem, the advice-giver, and the recipient. Southern Journal of Communication, 71(1), $67-85$.

Fitzsimons, G. M., \& Shah, J. Y. (2009.) Confusing one instrumental other for another: Goal effects on social categorization. Psychological Science, 20, 1468-1472.

French, J. R. \& Raven, B. H. (1959). The bases of social power. In D. Cartwright (Ed.), Studies of Social Power (pp. 150 - 167). Ann Arbor: Institute for Social Research, University of Michigan. 
Galinsky, A. D., Gruenfeld, D. H, \& Magee, J. C. (2003). From power to action. Journal of Personality and Social Psychology, 85, 453-466.

Galinsky, A. D., Magee, J. C., Gruenfeld, D. H., Whitson, J. A., \& Liljenquist, K. A. (2008). Power reduces the press of the situation: Implications for creativity, conformity, and dissonance. Journal of Personality and Social Psychology, 95, 1450-1466.

Gino, F. (2008). Do we listen to advice just because we paid for it? The impact of cost of advice on its use. Organizational Behavior and Human Decision Processes, 107(2), 234-245.

Gino, F., \& Moore, D. A. (2007). Effects of task difficulty on use of advice. Journal of Behavioral Decision Making, 20(1), 21-35.

Gino, F., \& Schweitzer, M. (2008). Blinded by anger or feeling the love: How emotions influence advice taking. Journal of Applied Psychology, 93(5), 1165-1173.

Gino, F., Shang, J., \& Croson, R. C. (2009). The impact of information from similar or different advisors on judgment. Organizational Behavior and Human Decision Processes, 108, 287-302.

Goldsmith, D.J., \& Fitch, K. (1997). The normative context of advice as social support. Human Communication Research, 23, 454-476.

Goodwin, S. A., Gubin, A., Fiske, S. T., \& Yzerbyt, V. (2000). Power can bias impression formation: Stereotyping subordinates by default and by design. Group Processes and Intergroup Relations, 3, 227-256.

Goodwin, S. A., Operario, D., \& Fiske, S. T. (1998). Situational power and interpersonal dominance facilitate bias and inequity. Journal of Social Issues, 54, 677-699. 
Gruenfeld, D. H., Inesi, M. E., Magee, J. C., \& Galinsky, A. D. (2008). Power and the objectification of social targets. Journal of Personality and Social Psychology, 95, 111127.

Harvey, N., \& Fischer, I. (1997). Taking advice: Accepting help, improving judgment, and sharing responsibility. Organizational Behavior and Human Decision Processes, 70, 117 133.

Hogarth, R. M. (1978). A note on aggregating opinions. Organizational Behavior and Human Decision Processes, 21, 40-46.

Hollenbeck, J. R., Ilgen, D. R., Sego, D. J., Hedlund, J., Major, D. A., \& Phillips, J. (1995). Multilevel theory of team decision making: Decision performance in teams incorporating distributed expertise. Journal of Applied Psychology, 80, 292-316.

Hollenbeck, J.R., Ilgen, D.R., LePine, J.A., Colquitt, J.A., \& Hedlund, J., (1998). Extending the multilevel theory of team decision making: Effects of feedback and experience in hierarchical teams. Academy of Management Journal, 41, 269-282.

Houston, J. M., Farese, D., \& La Du, T. J. (1992). Assessing competitiveness: A validation study of the Competitiveness Index. Personality and Individual Differences, 13, 10, 1153-1156.

Humphrey, S.E., Hollenbeck, J.R., Meyer, C.J., \& Ilgen, D.R. (2002). Hierarchical team decision making. In G.R. Ferris and J.J. Martocchio (Eds). Research in personnel and human resources management (vol. 21, pp. 175-213). Stamford, CT: JAI Press.

Keltner, D., Gruenfeld, D. H., \& Anderson, C. (2003). Power, approach, and inhibition. Psychological Review, 110, 265-284.

Kim, P. H., Pinkley, R. L., \& Fragale, A. R. 2005. Power dynamics in negotiation. Academy of Management Review, 30: 799-822. 
Koestner, R., Gingras, I., Abutaa, R., Losier, G.F., DiDio, L., \& Gagné, M. (1999). To follow expert advice when making a decision: An examination of reactive versus reflective autonomy. Journal of Personality, 65, 851-872.

Krueger, J. I. (2003). Return of the ego-self-referent information as a filter for social prediction: Comment on Karniol (2003). Psychological Review, 110, 585-590.

Ku, G., Malhotra, D., \& Murnighan, J. K. (2005). Towards a competitive arousal model of decision-making: a study of auction fever in live and internet auctions. Organizational Behavior and Human Decision Processes, 96, 89-103.

Langer, E. J. (1975). The illusion of control. Journal of Personality and Social Psychology, 32(2), 311-328.

Larrick, R. P. (2009). Broaden the decision frame to make effective decisions. In E. A. Locke (Ed.), Handbook of Principles of Organizational Behavior (2nd Ed.). Wiley and Sons.

Larrick, R. P., \& Soll, J. B. (2009). Strategies for revising judgment: How (and how well) people use others' opinions. Journal of Experimental Psychology: Learning, Memory, and Cognition, 35(3), 780-805.

Larrick, R. P., \& Soll, J. B. (2006). Intuitions about combining opinions: Misappreciation of the averaging principle. Management Science, 52, 111-127.

Lawrence, M. \& Warren, M. (2003, November). Are judgmental forecasts impacted by the source of the advice? Paper presented at the annual meeting of the Society for Judgment and Decision Making, Vancouver, BC.

Lee, F. (1997). When the going gets tough, do the tough ask for help? Help seeking and power motivation in organizations. Organizational Behavior and Human Decision Processes, 72(3), 336-363. 
Lerner, J. S., \& Tiedens, L. Z. (2006). Portrait of the angry decision maker: How appraisal tendencies shape anger's influence on cognition. Journal of Behavioral Decision Making, $19,115-137$.

MacKinnon, D. P., Fairchild, A. J., \& Fritz, M. S. (2007). Mediation analysis. Annual Review of Psychology, 58, 593-614.

Magee, J. C., Galinsky, A. D., \& Gruenfeld, D. H. (2007). Power, propensity to negotiate, and moving first in competitive interactions. Personality and Social Psychology Bulletin, 33, 200-212.

Malhotra, D., Ku, G., \& Murnighan, J. K. (2008, May). When winning is everything. Harvard Business. Review, 85, 78-86.

Overbeck, J. R., \& Park, B. (2006). Powerful perceivers, powerless objects: Flexibility of powerholders' social attention. Organizational Behavior and Human Decision Processes, 99(2), 227-243.

Patt, A., Bowles, H. R., \& Cash, D. (2006). Mechanisms for enhancing the credibility of an adviser: Prepayment and aligned incentives. Journal of Behavioral Decision Making, 19, 347-359.

Pfeffer, J., \& Fong, C. T. (2005). Building organization theory from first principles: The selfenhancement motive and understanding power and influence. Organization Science, 16, $372-388$.

Phillips, J. M. (1999). Antecedents of leader utilization of staff input in decision-making teams. Organizational Behavior and Human Decision Processes, 77, 215-242. 
See, K. E., Morrison, E. W., Rothman, N. B., \& Soll, J. B. (2010). Powerful and unpersuaded: The implications of power for confidence, advice-taking, and accuracy. Working paper: Stern School of Business, New York University.

Shrout, P. E., \& Bolger, N. (2002). Mediation in experimental and non-experimental studies: New procedures and recommendations. Psychological Methods, 7, 422-445.

Sivanathan, N., \& Galinsky, A. D. (June, 2007). Power and overconfidence. Paper presented at the annual International Association for Conflict Management Conference, Budapest, Hungary.

Smither, R. D., \& Houston, J. M. (1992). The nature of competitiveness: The development and validation of the Competitiveness Index. Educational and Psychological Measurement, $52,407-418$.

Sniezek, J. A., \& Buckley, T. (1995). Cueing and cognitive conflict in judge-advisor decision making. Organizational Behavior and Human Decision Processes, 62, 159-174.

Sniezek, J. A., \& Van Swol, L. M. (2001). Trust, confidence, and expertise in a judge-advisor system. Organizational Behavior and Human Decision Processes, 84, 288-307.

Sniezek, J. A., Schrah, G. E., \& Dalal, R. S. (2004). Improving judgment with prepaid expert advice. Journal of Behavioral Decision Making, 17, 173-190.

Soll, J. B., \& Larrick, R. P. (2009). Strategies for revising judgment: How (and how well) people use others' opinions. Journal of Experimental Psychology: Learning, Memory, and Cognition, 35, 780-805.

Soll, J. B., \& Mannes, A. E. (in press). International Journal of Forecasting.

Surowiecki, J. (2004). The Wisdom of crowds: Why the many are smarter than the few and how collective wisdom shapes business, economies, societies and nations. Little, Brown. 
Taylor, S. E., \& Brown, J. D. (1988). Illusion and well-being - a social psychological perspective on mental-health. Psychological Bulletin, 103(2), 193-210.

Thibaut, J. W., \& Kelley, H. H. (1959). The social psychology of groups. New York: Wiley.

Thompson, S. C., Armstrong, W., \& Thomas, C. (1998). Illusions of control, underestimations, and accuracy: A control heuristic explanation. Psychological Bulletin, 123(2), 143-161.

Van Kleef, G. A., Oveis, C., Van der Löwe, I., LuoKogan, A., Goetz, J., \& Keltner, D. (2008). Power, distress, and compassion: Turning a blind eye to the suffering of others. Psychological Science, 19, 1315-1322.

Van Swol, L. M. \& Sniezek, J. A. (2005). Factors affecting the acceptance of expert advice. British Journal of Social Psychology, 44, 443-461.

Westphal, J. D. (1999). Collaboration in the boardroom: Behavioral and performance consequences of CEO-board social ties. Academy of Management Journal, 42, 7-24.

Yaniv, I. (2004). Receiving other people's advice: Influence and benefit. Organizational Behavior and Human Decision Processes, 93(1), 1-13.

Yaniv, I., \& Foster, D. P. (1997). Precision and accuracy of judgmental estimation. Journal of Behavioral Decision Making, 10, 21-32.

Yaniv, I., \& Kleinberger, E. (2000). Advice taking in decision making: Egocentric discounting and reputation formation. Organizational Behavior and Human Decision Processes, 83(2), 260-281.

Yaniv, I., \& Milyavsky, M. (2007). Using advice from multiple sources to revise and improve judgment. Organizational Behavior and Human Decision Processes, 103, 104-120. 


\section{Footnotes}

${ }^{1}$ In Experiments 1 and 2, no participants guessed the same weight as the advice across rounds, and all values for WOA were within the range -1 to 1 . In Experiment 3 there was one person who guessed the same weight as the advice for the third target (none for the first two); that participant's WOA for that target was removed from the computation of their average WOA. In addition, there were 15 people with WOA $>1$ or $<-1$ for the first target, 3 for the second target, and 23 for the third target. These were treated as $\mathrm{WOA}=1$ (or -1 for negative values) in computing the average WOA as in previous research (e.g., Gino et al., 2009). In Experiment 4, there was one person who guessed the same weight as the advice for the first target and one person for the third target (none for the second target); that participant's WOA for that target was removed from the computation of their average WOA. In addition, there were 6 people with WOA $>1$ or $<-1$ for the first target, 5 for the second target, and 11 for the third target. These were treated as $\mathrm{WOA}=1$ (or -1 for negative values) in computing the average WOA. In addition, WOA values greater than 3 standard deviations from the mean were excluded from the analyses.

${ }^{2}$ We coded participants' essays to determine whether they included any mention of competitive content. Specifically, two independent raters (who were blind to the study hypotheses) read each essay and then indicated whether it described a competitive situation or not. Similar to the coding of the power prime essays described in Galinsky, Gruenfeld, and Magee (2003), participants described different types of relationships (e.g., teacher-student, employer-employee). Yet, independent of the relationship described or the experimental condition, the results of the coding indicated that participants' essays did not include competitive content. 
${ }^{3}$ High power and control participants rarely used advice in place of their own opinion $(\mathrm{WOA}=1)-3.0 \%$ and $8.1 \%$ of the time, respectively — whereas low power individuals used advice in place of their own opinion frequently $-37.8 \%$ of the time. Participants differed little in their use of averaging $(.4<\mathrm{WOA}<.6)$, ranging from $8 \%$ to $16 \%$ across the 3 cells.

${ }^{4}$ High power individuals rarely used novice and expert advice in place of their own opinion $(\mathrm{WOA}=1)-9.1 \%$ and $8.8 \%$ of the time, respectively—whereas low power individuals used novice and expert advice in place of their own opinion more often-30.3\% and $50.0 \%$ of the time, respectively. Participants differed little in their use of averaging, ranging from $0 \%$ to $13 \%$ across the 4 cells.

${ }^{5}$ High power individuals rarely used novice and expert advice in place of their own opinion $(\mathrm{WOA}=1)-3.8 \%$ and $6.7 \%$ of the time, respectively — whereas low power individuals used novice and expert advice in place of their own opinion more often-20.0\% and $34.7 \%$ of the time, respectively. Participants differed little in their use of averaging, ranging from $10 \%$ to $16 \%$ across the 4 cells.

${ }^{6}$ Participants in the competition condition rarely used novice and expert advice in place of their own opinion $(\mathrm{WOA}=1)-6.0 \%$ and $6.9 \%$ of the time, respectively. Participants in the cooperation condition rarely used novice advice in place of their own opinion (9.3\% of the time), but participants in the cooperation condition used expert advice in place of their own $17.6 \%$ of the time. Participants differed little in their use of averaging, ranging from $12.1 \%$ to $17.6 \%$ across the 4 cells. 
Table 1

Differences in effects for moderated mediation analyses (Study 3)

First stage effect of Indirect effect of

Power on Power on WOA

Competitiveness through

Competitiveness

and Confidence

Novice

0.22

$-.01$

Expert

$1.38^{* * *}$

$-0.05 * * *$

Difference

$1.16^{* *}$

$-.04 * * *$

Note: entries are non-standardized regression coefficients.

${ }^{*} p<.05,{ }^{* *} p<.01, * * * p<.001$ 
Table 2

Experiment 4: Analysis of Simple Effects

\begin{tabular}{lccccc}
\hline \multicolumn{1}{c}{ Moderator: } & \multicolumn{2}{c}{ Stage } & \multicolumn{3}{c}{ Effect } \\
\cline { 2 - 6 } Competition & First & Second & Direct & Indirect & Total \\
Cooperation (0) & $-.89 * *$ & $-.13^{* *}$ & $.14^{*}$ & $.12^{* *}$ & $.26^{* *}$ \\
Competition (1) & .04 & $-.20^{* *}$ & .07 & -.01 & .06 \\
Differences & $.93^{*}$ & $-.07^{*}$ & -.07 & $-.12^{*}$ & $-.19^{*}$ \\
\hline
\end{tabular}

Note: entries are non-standardized regression coefficients.

$* p<.05,{ }^{* *} p<.01,{ }^{* * *} p<.001$ 


\section{Figure Captions}

Figure 1. Path model for moderated mediation.

Figure 2. Mean WOA values by condition, Experiment 1. Error bars represent standard errors.

Figure 3. Mean WOA values by condition, Experiment 2. Error bars represent standard errors. Figure 4. Mean WOA values by condition, Experiment 3. Error bars represent standard errors.

Figure 5. Interaction between advisor expertise and power on competitiveness, Experiment 3. Figure 6. Mean WOA values by condition, Experiment 4. Error bars represent standard errors.

Figure 1

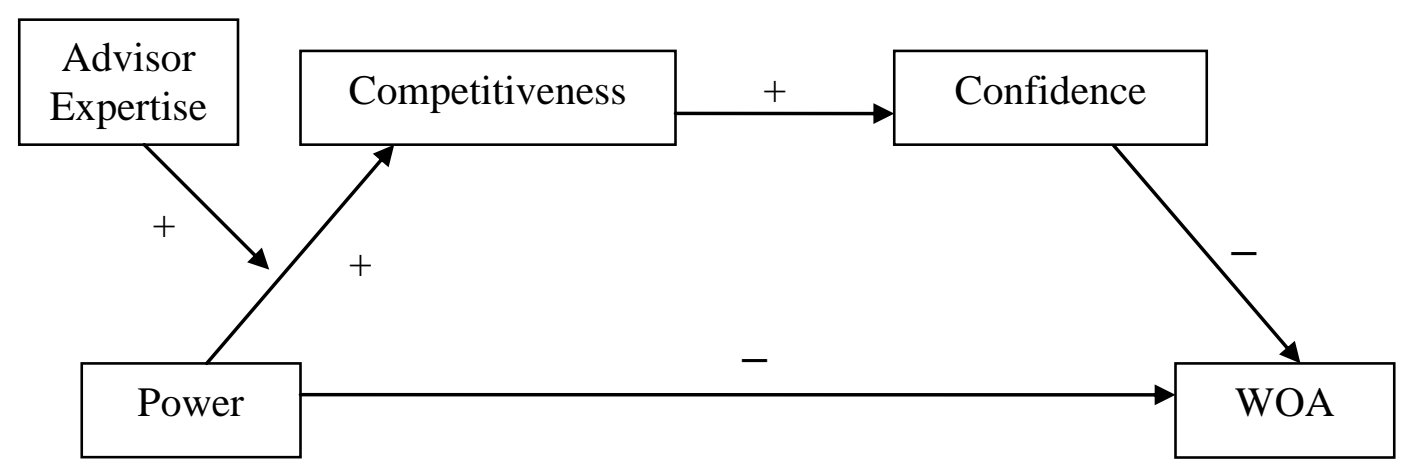


Figure 2

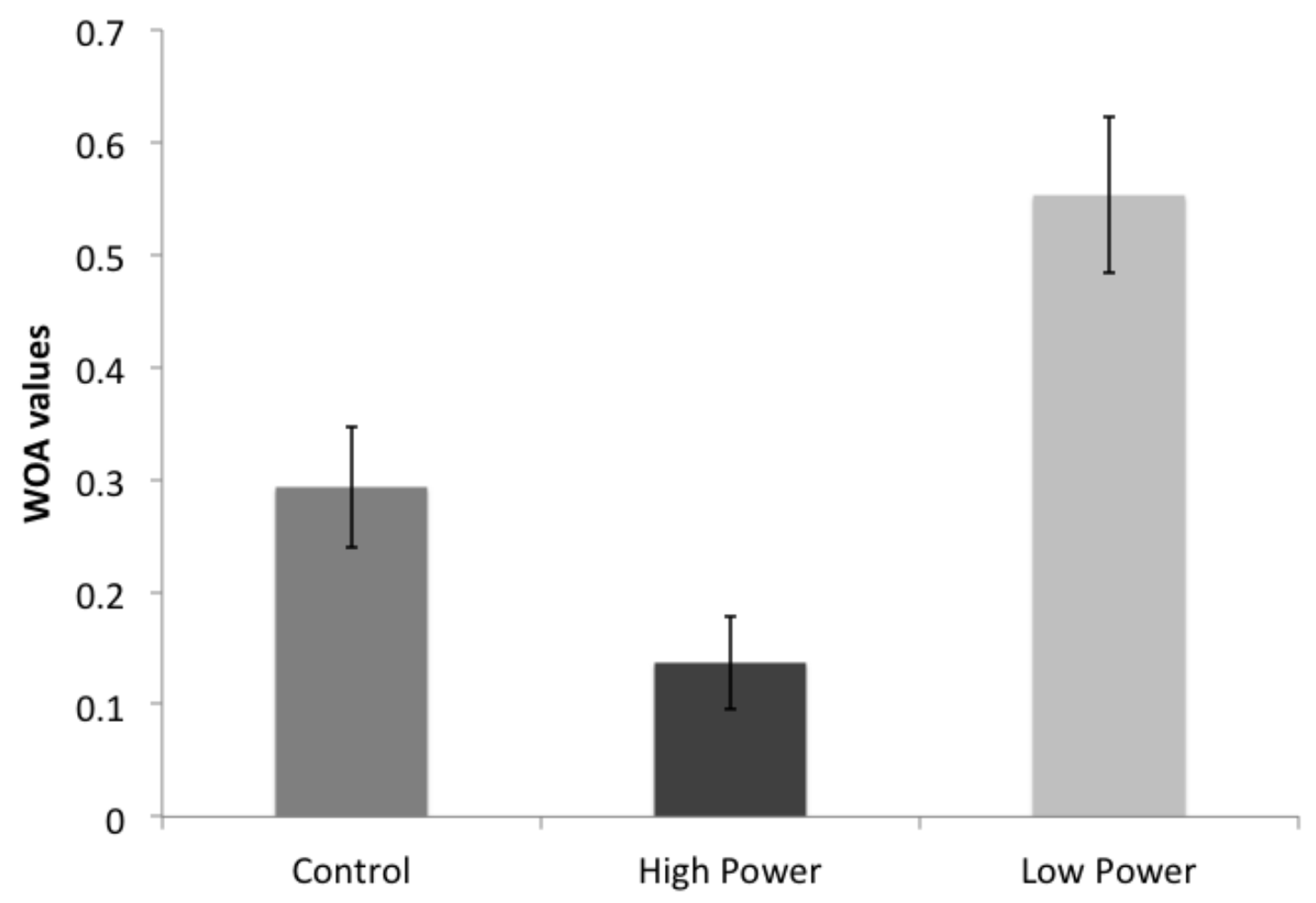


Figure 3

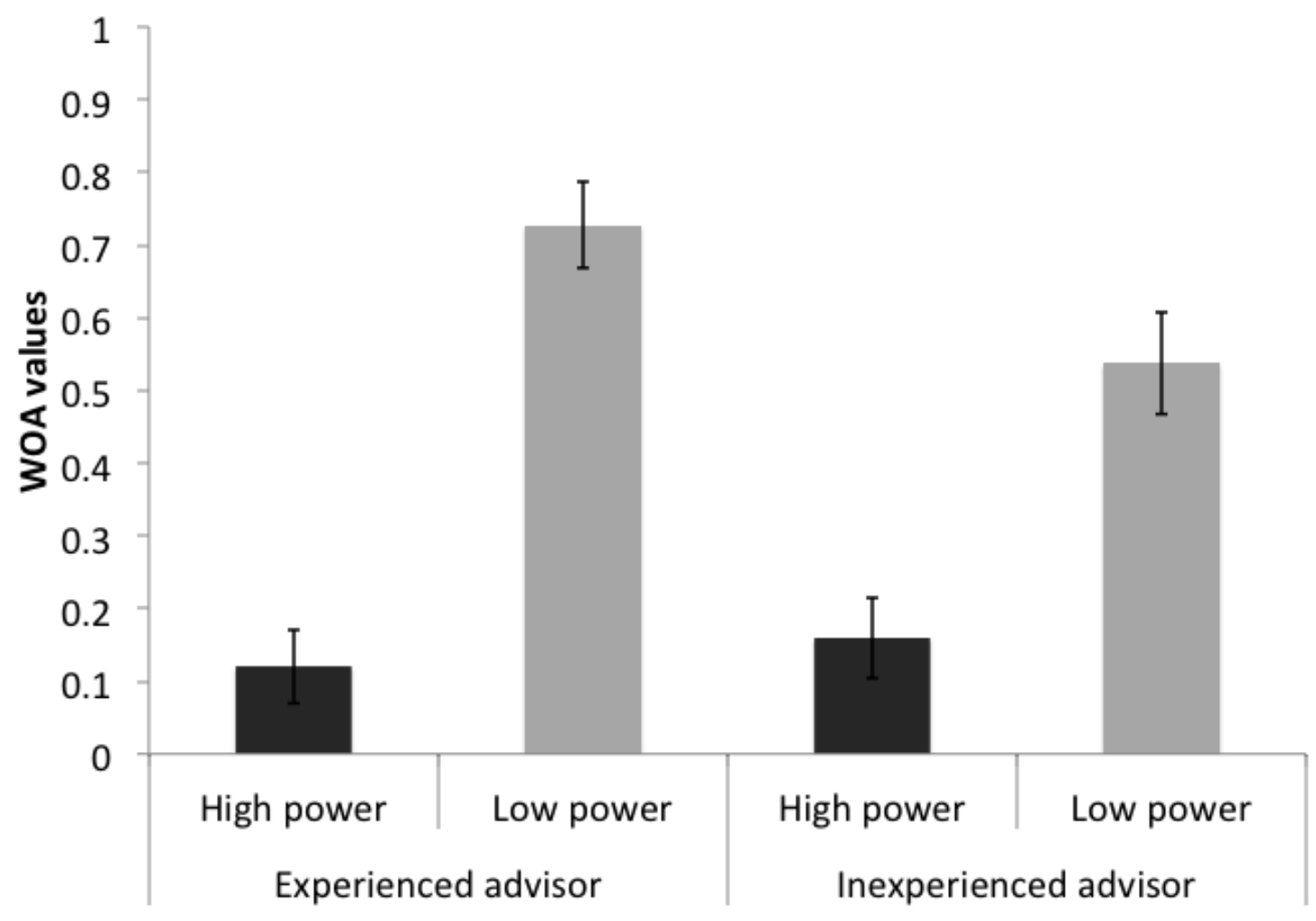


Figure 4

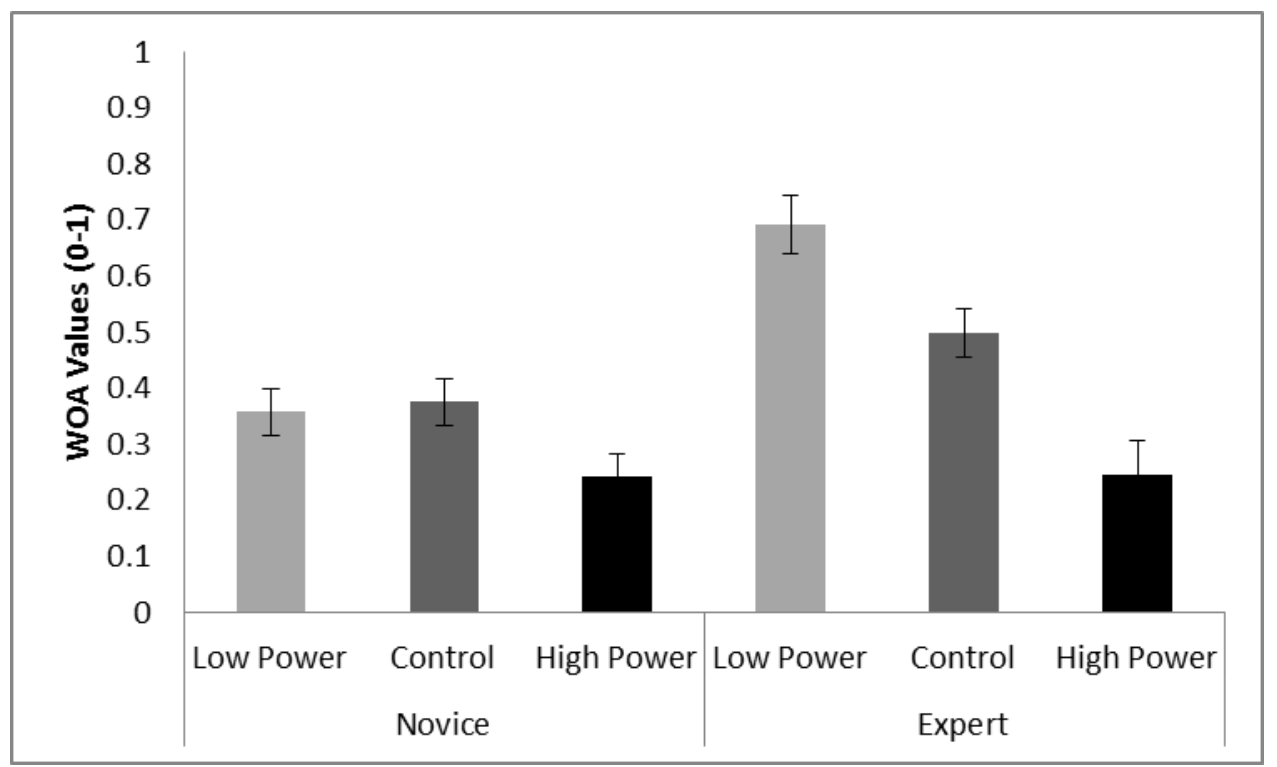


Figure 5

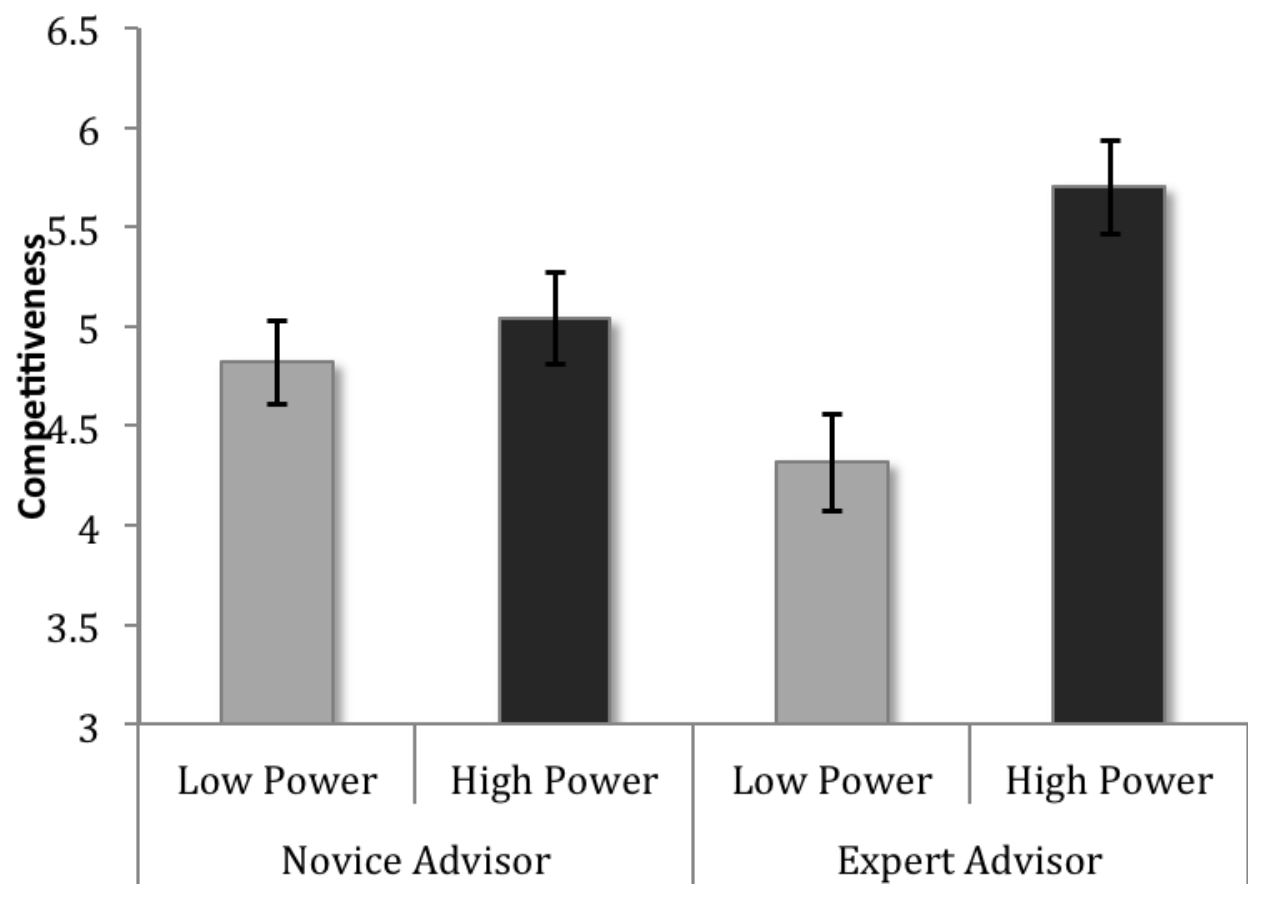


Figure 6

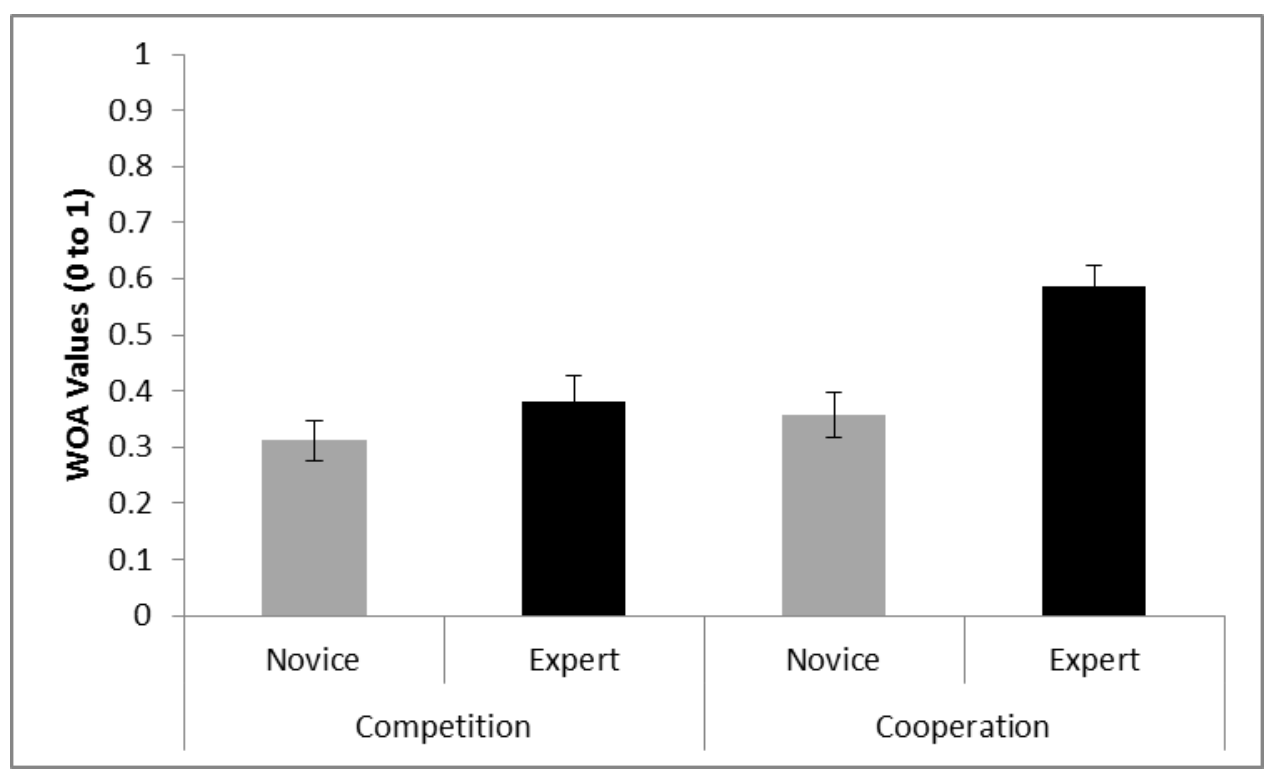

